\title{
Sistem Pengendalian Internal Atas Piutang Menggunakan Metode Analisis Umur Piutang (Aging Schedule) Pada CV. AGS'NIE
}

\author{
Widya Jati Lestari ${ }^{1}$, Marsani Asfi ${ }^{2}$, Arum Setiawati ${ }^{3}$ \\ Sekolah Tinggi Informatika Dan Komputer Catur Insan Cendekia \\ Jl. Kesambi No 202 Cirebon \\ Widya.jatilestari@cic.ac.id, marsani.afsi@cic.ac.id, arumsetiawati11@gmail.com
}

\begin{abstract}
Abstrak
CV. AGS'NIE merupakan salah satu bentuk perusahaan yang bergerak di bidang distributor produk kosmetikyang beralamat di Villa Intan II Blok J9 Cirebon. Penjualan kredit CV Ags'nie kurang memperhatikan resiko yang timbul yaitu kerugian piutang apabila perusahaan tidak dapat menagihnya. Pada perusahaan ini belum memiliki catatan yang akuntabel dan belum menggunakan perhitungan piutang yang baik menurut standar akuntansi keuangan (SAK). Berdasarkan masalah tersebut maka dibuat aplikasi sistem pengendalian internal atas piutang menggunakan metode analisis umur piutang (aging schedule) pada CV. AGS'NIE. Metode yang digunakan adalah metode analisis umur piutang. Aplikasi yang dibuat dengan Bahasa pemrograman PHP serta database MySQL. Terdapat 2 user aplikasi yaitu bagian akuntansi dan manager. Analisis umur piutang mengelompokkan umurnya berdasarkan atas tanggal jatuh tempo piutang, yang dibagi ke dalam klasifikasi: belum jatuh tempo dicadangkan sebesar 5\%, telah jatuh tempo 1-14 hari dicadangkan sebesar 10\%, telah jatuh tempo 14-20 hari dicadangkan sebesar 15\%, telah jatuh tempo 20-30 hari dicadangkan sebesar 20\%, dan telah jatuh tempo diatas 30 hari dicadangkan sebesar 25\%.Pengendalian internal adalah salah satu cara yang digunakan untuk mengantisipasi kecurangan dan mengantisipasi kemungkinan piutang tak tertagih, dengan adanya pengendalian piutang dapat meminimalisasi kerugian yang di akibatkan piutang tak tertagih.Piutang merupakan sejumlah tagihan yang akan diterima oleh perusahaan dalam bentuk kas dari pihak lain, baik sebagai akibat penyerahan barang dan jasa secara kredit maupun sebagai akibat kelebihan pembayaran kas kepada pihak lain.
\end{abstract}

Kata kunci:Sistem, Pengendalian Internal, Metode Analisis Umur Piutang

\begin{abstract}
$C V$. AGS'NIE is one of the companies engaged in the distributor of cosmetic products having its address at Villa Intan II Blok J9 Cirebon. CV Ags'nie credit sales pay less attention to the risks that arise, namely loss of accounts receivable if the company cannot collect them. This company does not have an accountable record and has not used good accounts receivable according to financial accounting standards (SAK). Based on these problems, an internal control system application for receivables is made using the aging schedule method on the CV. AGS'NIE. The method used is the method of age analysis of accounts receivable. Application made with PHP programming language and MySQL database. There are 2 user applications, accounting and manager. Analysis of the age of accounts receivable classifies their age based on the maturity date of the receivables, which are divided into classifications: not yet backed up by 5\%, maturity 1-14 days reserved at 10\%, maturity 14-20 days reserved at 15\%, has been due for 20-30 days in reserve of 20\%, and has been due above 30 days reserved for $25 \%$. Internal control is one way that is used to anticipate fraud and anticipate the possibility of uncollectible accounts, with the control of accounts receivable can minimize losses caused by uncollectible accounts. Receivables are a number of bills the company will receive in the form of cash from other parties, both as a result of the delivery of goods and services on credit or as a result of excess cash payments to other parties.
\end{abstract}

Keywords:System, Internal Control, Methods of Age Analysis of Receivables 


\section{PENDAHULUAN}

Ditengah persaingan bisnis yang ketat, perusahaan dituntut untuk mampu menguasai pasar, sehingga perusahaan perlu melakukan strategi penjualan agar jumlah penjualan meningkat. Berbagai cara dilakukan oleh perusahaan untuk meningkatkan jumlah penjualannya agar mencapai keuntungan semaksimal mungkin. Pengendalian internal merupakan suatu proses yang dipengaruhi oleh sumber daya manusia dan sistem teknologi informasi, yang dirancang untuk membantu organisasi mencapai suatu tujuan tertentu. Pengendalian internal berfungsi untuk mengarahkan, mengawasi dan mengukur sumber daya suatu organisasi. Pengendalian internal adalah salah satu cara yang digunakan untuk mengantisipasi kecurangan dan mengantisipasi kemungkinan piutang tak tertagih, dengan adanya pengendalian piutang dapat meminimalisasi kerugian yang di akibatkan piutang tak tertagih.

Piutang merupakan sejumlah tagihan yang akan diterima oleh perusahaan dalam bentuk kas dari pihak lain, baik sebagai akibat penyerahan barang dan jasa secara kredit maupun sebagai akibat kelebihan pembayaran kas kepada pihak lain. Pada umumnya pelanggan akan menjadi lebih tertarik untuk membeli sebuah produk yang ditawarkan secara kredit oleh perusahaan.

CV. AGS'NIE merupakan salah satu bentuk perusahaan yang bergerak di bidang distributor produk kosmetik. CV. AGS'NIE berdiri pada tahun 2009 yang beralamat di Villa Intan II Blok J9 Cirebon. Penjualan yang dapat dilakukan adalah secara tunai maupun kredit. Penjualan kredit CV Ags'nie kurang memperhatikan resiko yang timbul yaitu kerugian piutang apabila perusahaan tidak dapat menagihnya. Pada perusahaan ini belum memiliki catatan yang akuntabel dan belum menggunakan perhitungan piutang yang baik menurut standar akuntansi keuangan (SAK).

Ada beberapa elemen yang harus diperhatikan agar pengendalian internal berjalan baik. Pertama adalah prosedur dan kebijakan yang mengikat dan jelas. Kedua adalah peralatan yang memadai, hal ini diharapkan dapat mendukung agar prosedur dan kebijakan berjalan lancar. Kemudian pengawasan terusmenerus dan evaluasi berkala. Sehingga kendala yang menyangkut sistem pengendalian internal dapat diatasi oleh perusahaan. Analisis umur piutang mengelompokkan umurnya berdasarkan atas tanggal jatuh tempo piutang, yang dibagi ke dalam klasifikasi: belum jatuh tempo, telah jatuh tempo 1-30 hari, telah jatuh tempo 31-60 hari, telah jatuh tempo 61-90 hari dan telah jatuh tempo diatas 90 hari. Keunggulan penggunaan metode analisa umur piutang dalam penaksiran yakni akan menghasilkan piutang usaha yang lebih mendekati kenyataan, karena penaksiran dilakukan kepada masing-masing debitur secara lebih teliti.

Berdasarkan latar belakang tersebut penulis akan mengangkat permasalahan mengenai pengendalian internal atas piutang menggunakan metode analisis umur piutang yang selanjutnya akan disajikan dalam bentuk skripsi yang berjudul "Sistem Pengendalian Internal Atas Piutang Menggunakan Metode Analisis Umur Piutang (Aging Schedule) pada CV. AGS'NIE”.

\section{METODE PENELITIAN}

\subsection{Jenis Penelitian}

Jenis penelitian yang lakukan adalah penelitian deskriptif dengan penelitian studi kasus. Penelitian deskriptif adalah suatu penelitian yang dilakukan dengan tujuan utama untuk memberikan gambaran atau deskripsi tentang suatu keadaan secara objektif. Desain penelitian ini digunakan untuk memecahkan atau menjawab permasalahan yang sedang dihadapi pada situasi sekarang.

Penelitian deskriptif juga berarti penelitian yang dimaksudkan untuk menjelaskan fenomena atau karakteristik individual, situasi atau kelompok tertentu secara akurat. Studi kasus dilakukan dengan cara meneliti suatu permasalahan melalui suatu kasus.

\subsection{Teknik Pengumpulan data}

1. Penelitian Lapangan

a. Metode Observasi

Metode Observasi merupakan kegiatan mengamati secara langsung tanpa mediator sesuatu objek untuk melihat dengan dekat kegiatan yang dilakukan objek tertentu.

b. Metode Wawancara

Wawancara merupakan percakapan antara periset seseorang yang berharap mendapatkan informasi, dan informan seseorang yang diasumsikan mempunyai informasi penting tentang sesuatu objek. 
2. Penelitian Kepustakaan

Penelitian kepustakaan merupakan metode pengumpulan data berdasarkan bukubuku yang berkaitan dengan topik skripsiini dan sumber-tertulis lainnya yang ada di perusahaan.

\section{HASIL DAN ANALISIS}

Tahap analisis dalam Unified Approach (UA) ditunjukkan untuk mengidentifikasi kelas-kelas yang terindentifikasi sebagai output ditahap analisis akan dijadikan input ditahap perancangan.

\subsection{Flowchart Manual}

Flowchartmanual pada gambar 1 adalah flowchart dan naratif yang sedang berjalan pada CV. AGS'NIE :

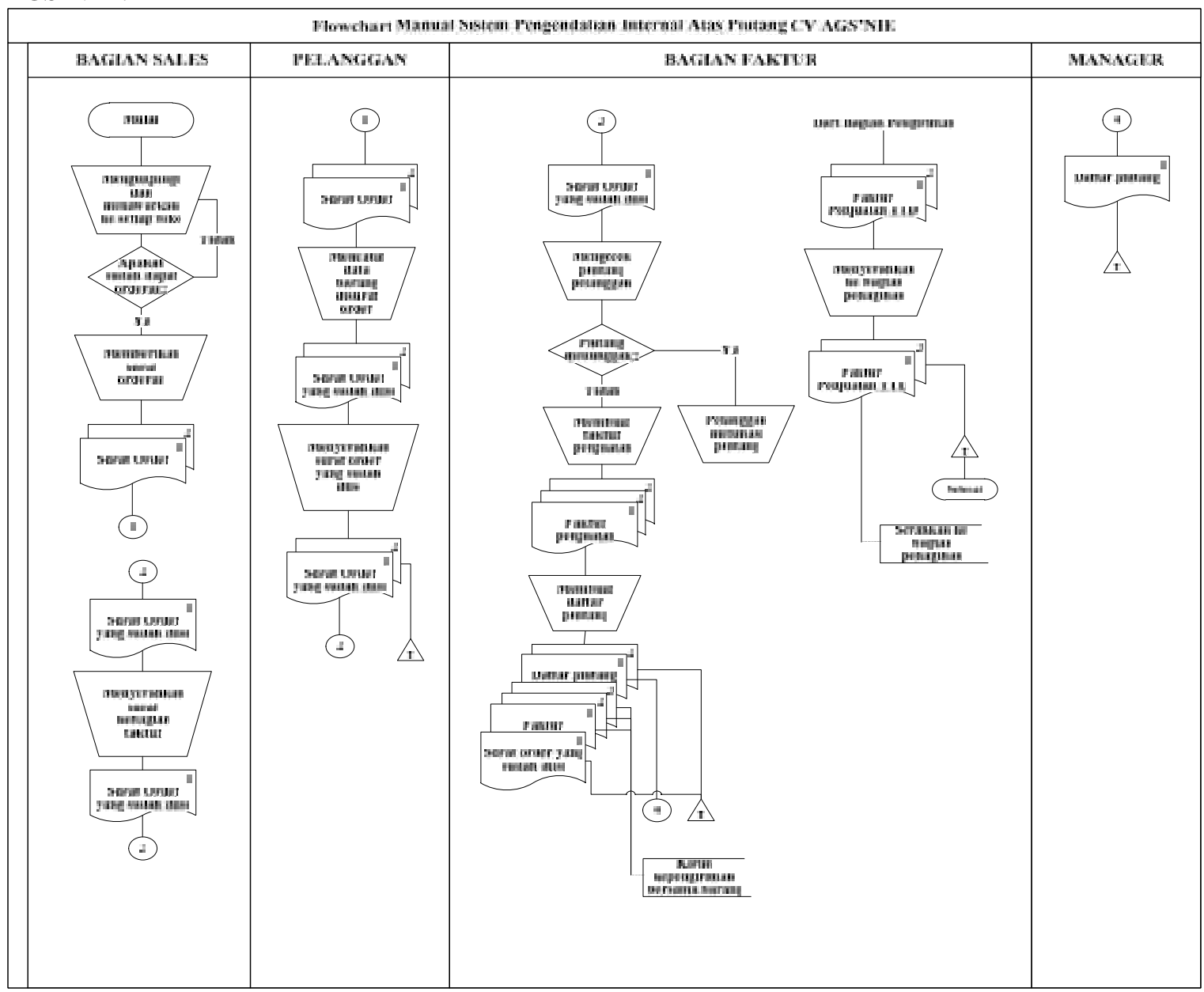

Gambar 1.Flowchart Manual

\subsection{Naratif Flowchart Manual Analisa Cadangan Kerugian Piutang}

a. Bagian Sales

Bagian sales mengunjungi dan menawarkan ke setiap toko jika sudah mendapatkan orderan, maka bagian sales akan memberikan surat orderan sebanyak ke 2 rangkap. Bagian sales menerima surat order yang sudah diisi dari pelanggan, kemudian menyerahkan surat order yang sudah diisi kebagian faktur.

b. Bagian Pelanggan

Pelanggan menerima surat order dari bagian sales lalu mencatat data barang disurat order tersebut. Kemudian menyerahkan surat order rangkap ke 1 yang sudah diisi ke bagian sales. 


\section{c. Bagian Faktur}

Bagian Faktur menerima surat order yang sudah diisi rangkap ke 1 dari bagian sales. Kemudian bagian faktur mengecek piutang pelanggan jika piutang pelanggan menunggak maka pelanggan harus melunasi piutang tersebut, sedangkan tidak menunggak maka akan langsung membuat faktur penjualan sebanyak 3 rangkap dan diserahkan ke bagian pengiriman. Kemudian bagian faktur membuat daftar piutang sebanyak 2 rangkap. Daftar piutang rangkap 1 akan diserahkan ke manager sedangkan daftar piutang rangkap ke 2 dan surat order yang sudah diisi rangkap ke 1 akan diarsip permanen berdasarkan tanggal. Bagian faktur menerima faktur penjualan rangkap 1 dan 3 dari bagian pengiriman kemudian faktur penjualan rangkap 1 diserahkan ke bagian penagihan serta faktur penjualan rangkap ke 3 akan diarsip permanen berdasarkan tanggal.

d. Manager

Manager menerima daftar piutang rangkap ke 1 dari bagian faktur kemudian diarsip permanen berdasarkan tanggal.

\subsection{Perancangan Diagram Flowchart Komputerisasi}

Diagram flowchart komputerisasisistem pengendalian internal atas piutang dengan menggunakan metode analisis umur piutang pada CV AGS'NIE terlihat pada gambar 2.:

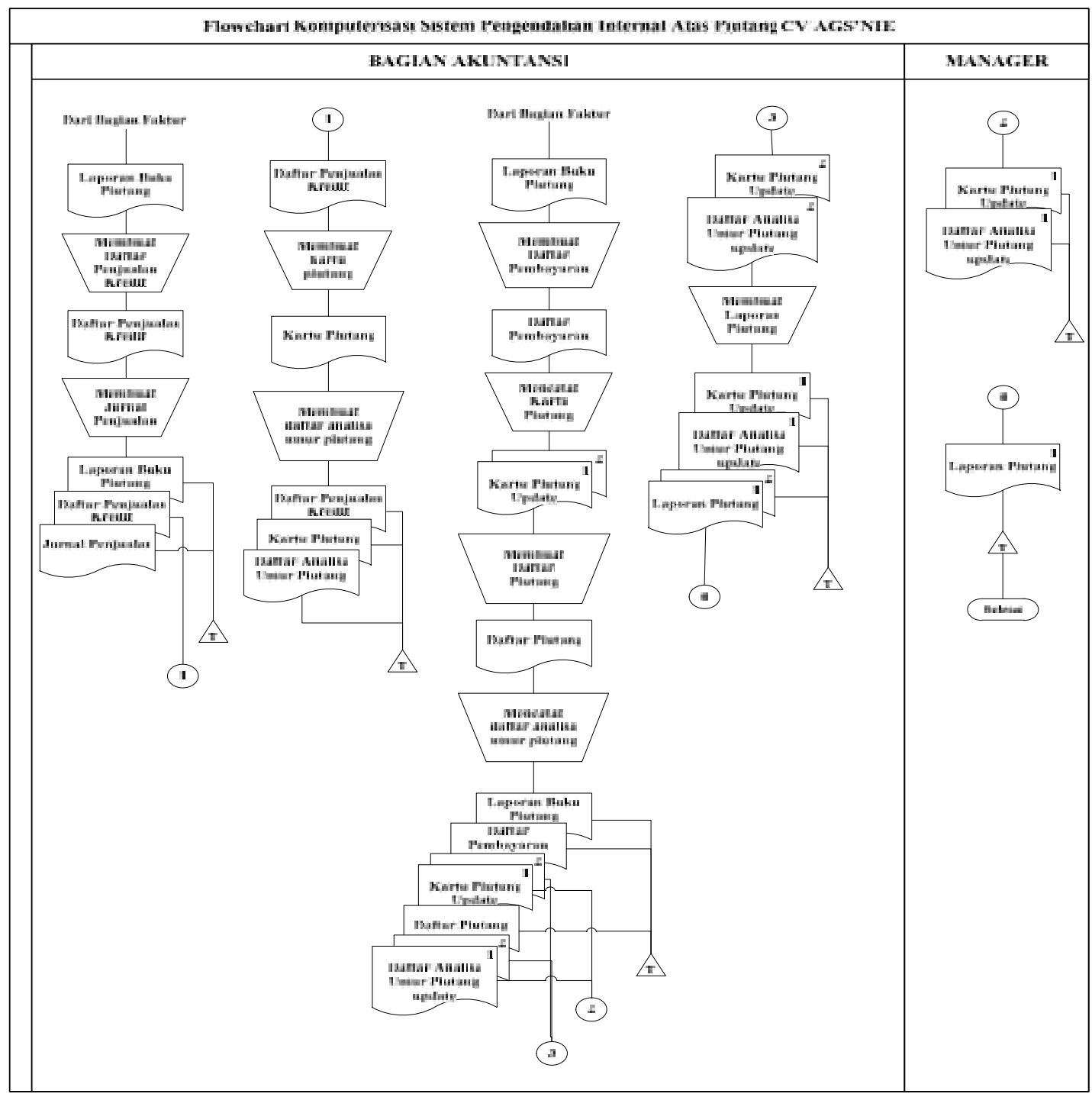

Gambar 2.Flowchart Komputerisasi 
3.4 Naratif Flowchart Komputerisasi Sistem Pengendalian Internal Atas Piutang Dengan Menggunakan Metode Analisis Umur Piutang Pada CV AGS'NIE:

a. Bagian Akuntansi

Bagian Akuntansi menerima laporan buku piutang dari bagian faktur. Kemudian bagian akuntansi membuat daftar penjualan kredit dan jurnal penjualan. Daftar penjualan kredit diarsip sementara dan laporan buku piutang dan jurnal penjualan diarsip secara permanen berdasarkan tanggal. Kemudian daftar penjualan kredit yang diarsip digunakan kembali untuk membuat kartu piutang dan daftar analisa umur piutang. Daftar penjualan kredit, kartu piutang dan daftar analisa umur piutang diarsip permanen berdasarkan tanggal. Bagian akuntansi menerima laporan buku piutang dari bagian faktur. Kemudian membuat daftar pembayaran, mencatat kartu piutang,daftar piutang dan daftar analisa umur piutang sebanyak 2 rangkap. Kartu piutang update dan daftar analisa umur piutang update rangkap ke 1 diberikan ke manager, kartu piutang update dan daftar analisa umur piutang update rangkap ke 2 diarsip sementara, sedangkan laporan buku piutang, daftar pembayaran dan daftar piutang diarsip permanen berdasarkan tanggal.Kartu piutang update dan daftar analisa umur piutang update rangkap ke 2 yang diarsip kemudian digunakan untuk membuat laporan piutang. Kartu piutang update, daftar analisa umur piutang update, dan laporan piutang rangkap ke 2 diarsip permanen berdasarkan tanggal, sedangkan laporan piutang rangkap ke 1 diberikan kepada manager.

b. Manager

Manager menerima kartu piutang, daftar analisa umur piutang update dan laporan piutang rangkap 1 dari bagian akuntansi kemudian diarsip permanen.

3.5 Perancangan Diagram Flowmap Komputerisasi

Perancangan Diagram flowmap komputerisasi yang dirancang dapat terlihat pada gambar 3; 


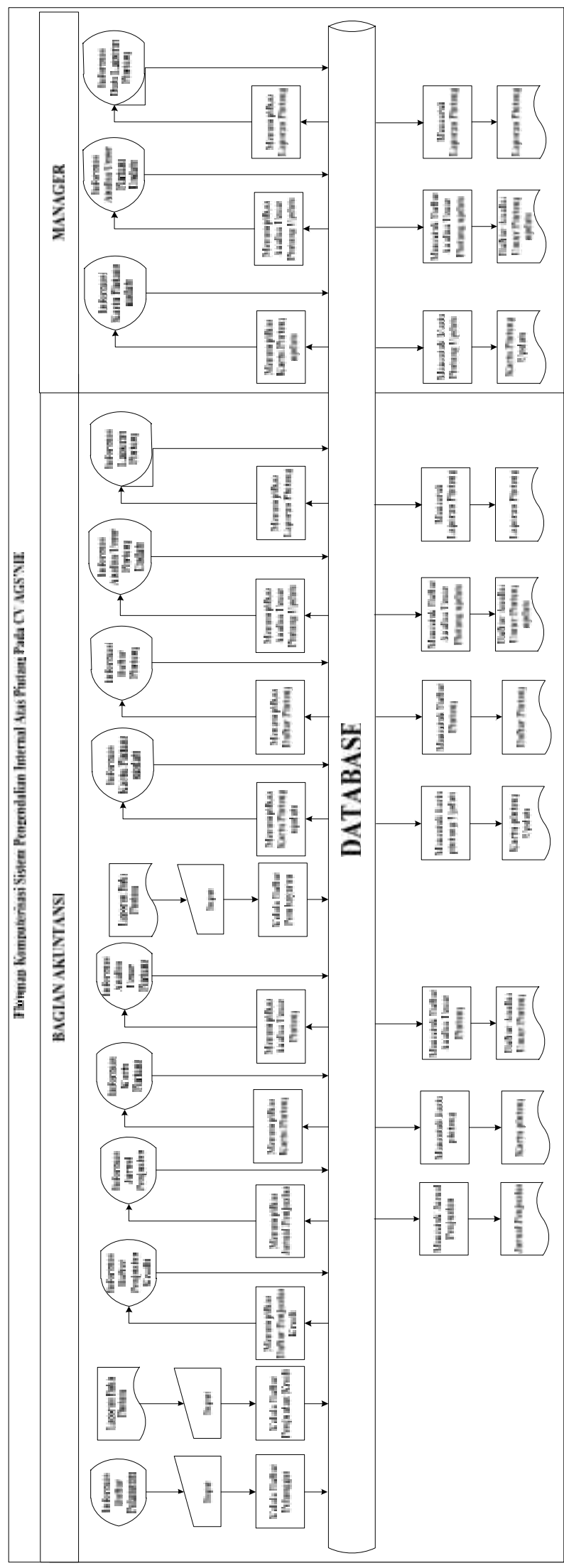

Gambar 3FlowmapKomputerisasi 


\subsection{Berikut Ini Naratif Flowmap Komputerisasi Sistem Pengendalian Internal Atas Piutang} Dengan Menggunakan Metode Analisis Umur Piutang Pada CV AGS'NIE:

a. Bagian Akuntansi

Bagian akuntansi dapat menginput daftar pelanggan. Kemudian bagian akauntansi mengelola penjualan kredit. Bagian akuntansi dapat menampilkan dan mencetak daftar penjualan kredit, jurnal penjualan, kartu piutang, analisa umur piutang. Kemudian bagian akuntansi menerima laporan buku piutang lalu menginput di daftar pembayaran. Bagian akuntansi juga dapat menampilkan dan mencetak kartu piutang update, daftar piutang, daftar analisa umur piutang update dan laporan piutang.

b. Manager

Manager dapat menampilkan dan mencetak kartu piutang update, daftar analisa umur piutang update dan laporan piutang.

\section{PENGUJIAN}

Pengujian merupakan proses terakhir untuk melakukan pemeriksaan dari hasil implementasi yang telah dilakukan pada aplikasi system pengendalian internal atas piutang menggunakan metode analisis umur piutang (aging schedule). Pengujian dilakukan untuk melihat fungsi-fungsi dari system apakah ada kekurangan dan kesalahan atau tidak.

Berikut merupakan tampilan aplikasi system pengendalian internal atas piutang menggunakan metode analisis umur piutang (aging schedule) pada CV AGS'NIE;

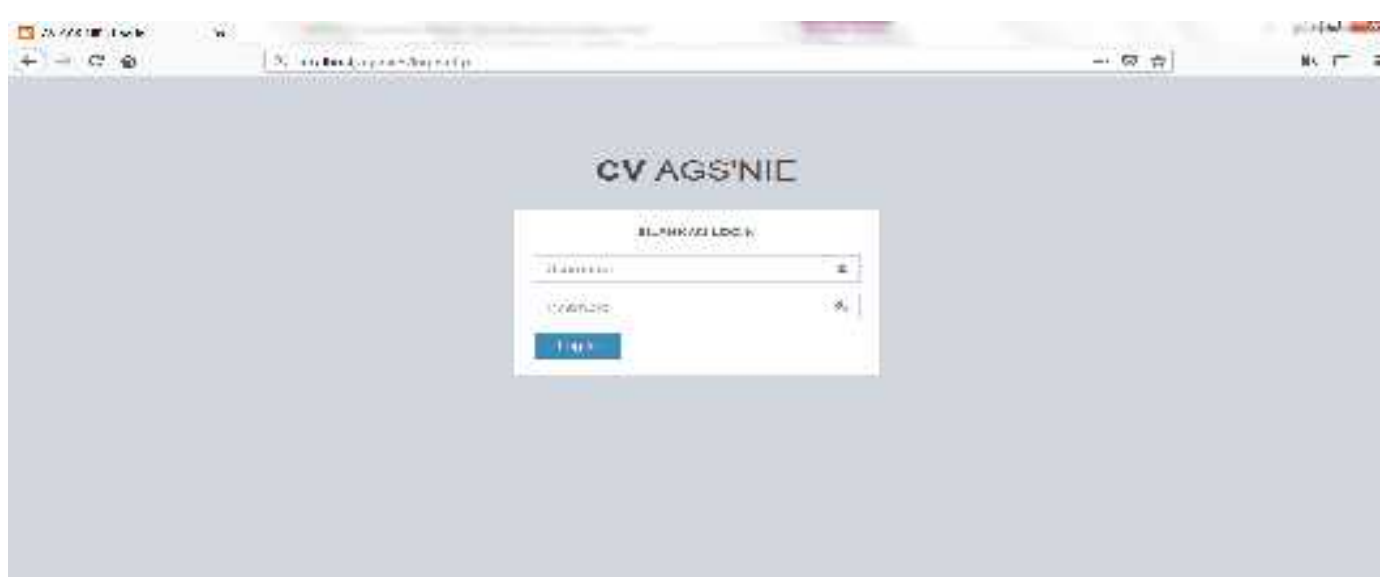

\section{Gambar 4.Form Login}

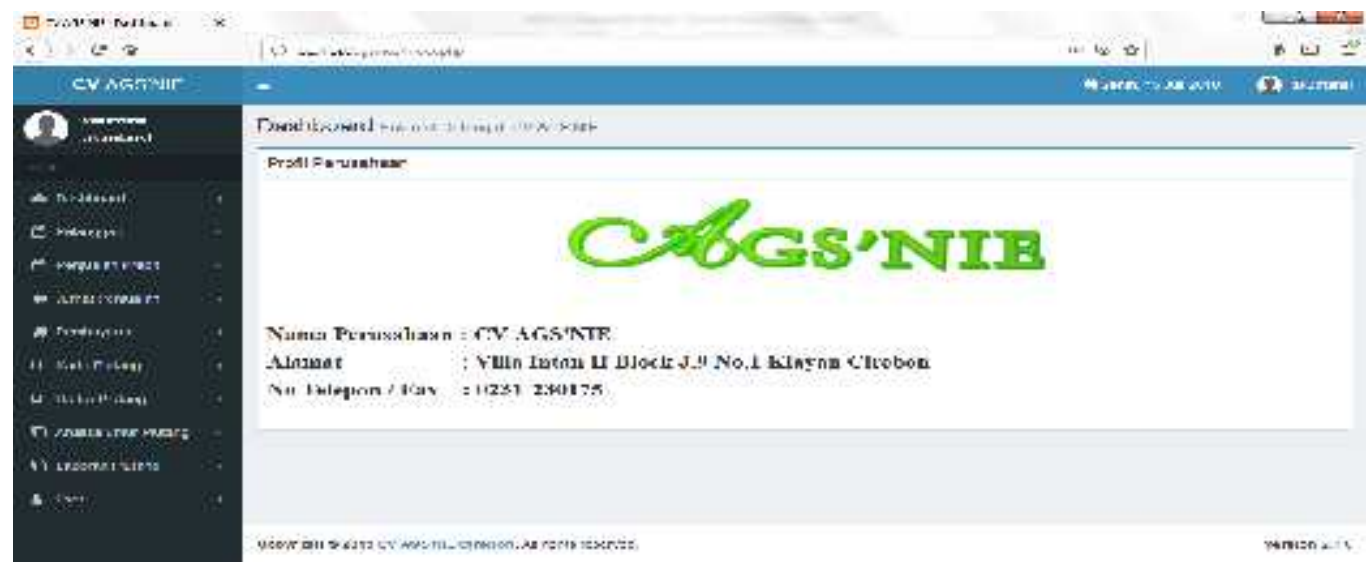

Gambar 5. Form Menu Utama Bagian Akuntansi 


\begin{tabular}{|c|c|c|c|c|c|c|c|c|c|c|c|c|}
\hline$\leftarrow \rightarrow 68$ & & 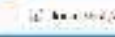 & 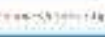 & 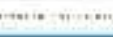 & & & & & $\omega$ & sis & $n$ & 1) $y=$ \\
\hline CVNGENL & & $=$ & & & & & & & & : ands & & 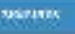 \\
\hline (9) wasent:- & & Perijusiar & I Kredil & & & & & & 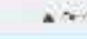 & a.., -4. & $\rightarrow 4 \quad \mathrm{n}$. & $\ldots n=0$ \\
\hline 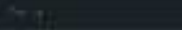 & & omeses & & & & & & & & & & \\
\hline th Lorus & & sen $)$ & $7=1 \ldots$ & & & & & & & \%.n. & & \\
\hline 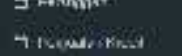 & , & 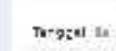 & 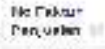 & coled & raimongen & Aleme & mmi- & Vmpos & 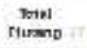 & Cabormen & tous & $\therefore=t e r$ \\
\hline a hitse-mant & & $w+\cdots$ & want & "ne: & 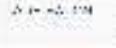 & SKUWN: & ath. & $+\cdots+\infty$ & $1,+1, m$ & (n) & nui.:. & $\psi:$ \\
\hline arvabuari & ' & 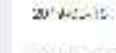 & $x \cos x$ & wasste & 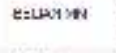 & 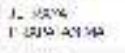 & Ir & Nitsib & 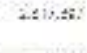 & 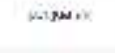 & $\begin{array}{l}\text { E.tut } \\
\text { Latr. }\end{array}$ & (A) \\
\hline - Lun lesere & 1 & $2 v+2=1$ & Met:es & westi & 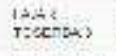 & 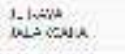 & ine & $30+2=1$ & catise & persenich & $\begin{array}{l}\text { Uest } \\
\text { Leire }\end{array}$ & H \\
\hline 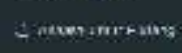 & + & $\Delta x+s$ & ases: & $\cos 2$ & $H=2 x=421$ & topasuese & Al. & $20+206=$ & sens: & Fetpor on & $\begin{array}{l}\text { cent, } \\
\text { waine }\end{array}$ & tat \\
\hline$=$ Leserano. & , & $20 x+2=1$ & yest:r & ostes: & $x \rightarrow=2-1$ & $\begin{array}{l}r: \pi \\
-3,4,1,4=0 .\end{array}$ & Nen & 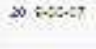 & $11.512 \%$ & pertenis & $\begin{array}{l}\text { East } \\
\text { Laice }\end{array}$ & tit \\
\hline 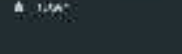 & t & $x+x=0$ & $\Leftrightarrow x=21$ & ates: & 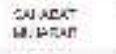 & cueste & Alw & $20+0201=$ & sis:2:2 & 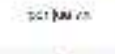 & $\begin{array}{l}\text { cent } \\
\text { lianst }\end{array}$ & tat \\
\hline & & 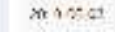 & $10000:-4$ & ort:? & i $\operatorname{LnT}$ & 1 and. & Nin & xis & ost 18 & 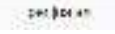 & $\begin{array}{l}n+3 n \\
1 . . .\end{array}$ & to: \\
\hline
\end{tabular}

Gambar 6.Form Daftar Penjualan Kredit

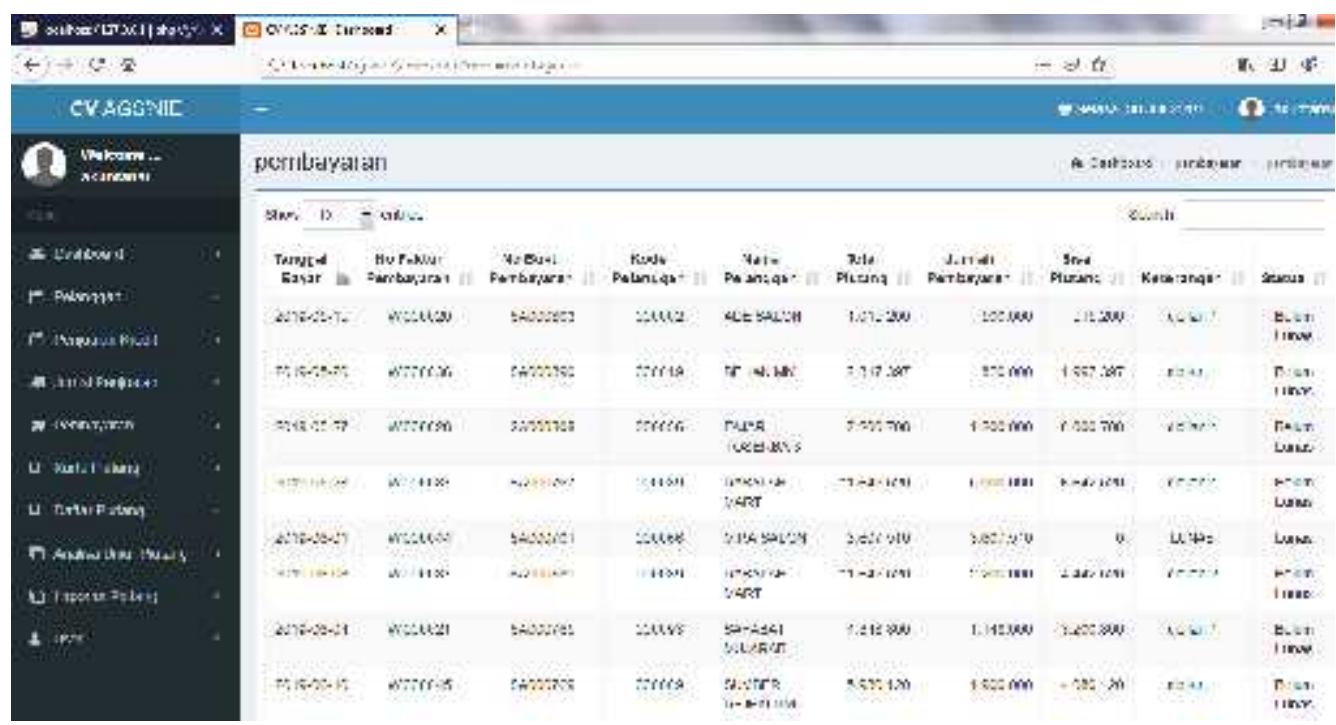

Gambar 7.Form Daftar Pembayaran

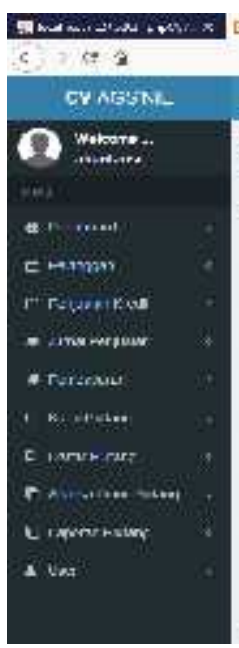

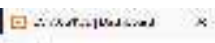

Q. A.e.

.., th th

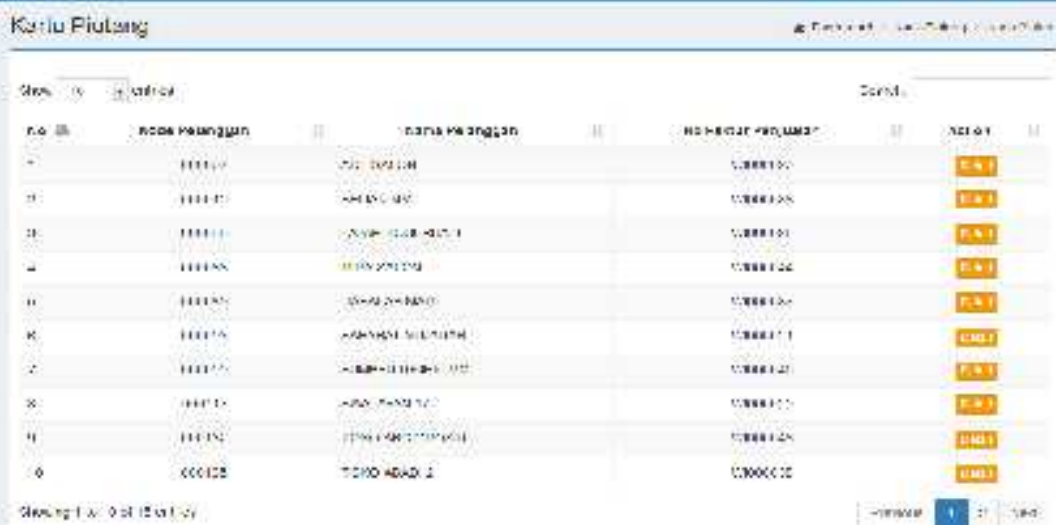

Gambar 8.Form Kartu Piutang 
JURNAL DIGIT Vol. 9, No.2Nov 2019, pp.215 224

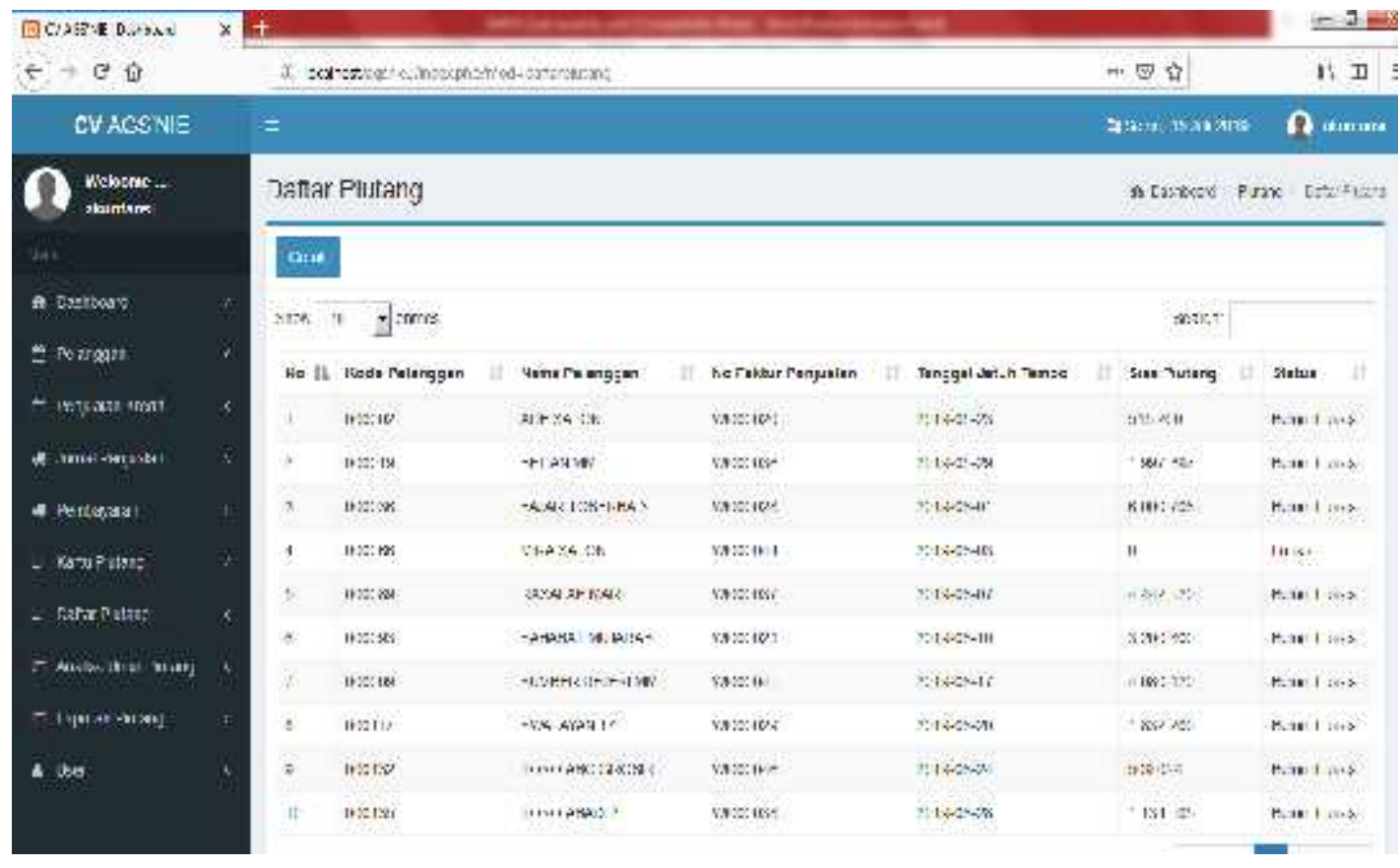

Gambar 9.Form Daftar Piutang

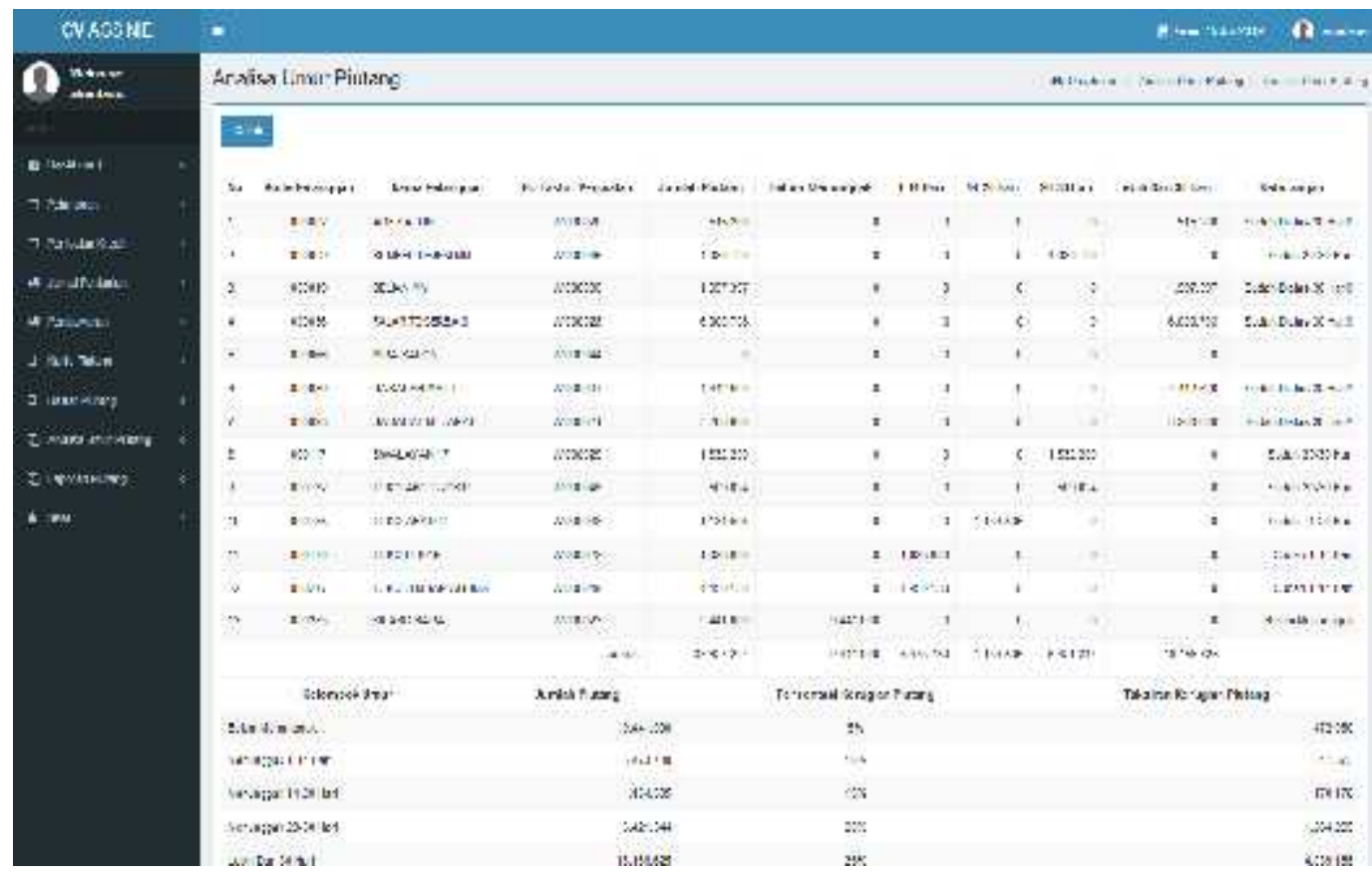

Gambar 10.Form Daftar Analisa Umur Piutang

\section{KESIMPULAN}

Berdasarkan penelitian yang telah dilakukan selama membuat system pengendalian internal atas piutang menggunakan metode analisis umur piutang (aging schedule) pada CV AGS'NIE, maka dapat diambil kesimpulan sebagai berikut:

1. Sistem pengendalian internal atas piutang menggunakan metode analisis umur piutang (aging schedule)pada cv ags'nie oleh 2 user yaitu bagian akuntansi dan manager. 
a. Bagian Akuntansi mengelola data pelanggan, data penjualan kredit, jurnal penjualan, data pembayaran piutang, kartu piutang, daftar piutang, analisa umur piutang dan laporan piutang.

b. Manager dapat melihat data kartu piutang, analisa umur piutang dan laporan piutang.

2. Dokumen-dokumen yang dihasilkan system pengendalian internal atas piutang menggunakan metode analisis umur piutang (aging schedule) adalah jurnal penjualan, kartu piutang, daftar piutang, daftar analisa umur piutang dan laporan piutang.

3. Pada system pengendalian internal atas piutang menggunakan metode analisis umur piutang (aging schedule) pada CV AGS'NIE, dapat mempermudah bagian akuntansi dalam pencatatan piutang yang akuntabel.

4. Pada system pengendalian internal atas piutang menggunakan metode analisis umur piutang (aging schedule) terlihat pada analisa umur piutang.

5. Analisis umur piutang mengelompokkan umurnya berdasarkan atas tanggal jatuh tempo piutang, yang dibagi ke dalam klasifikasi: belum jatuh tempo dicadangkan sebesar 5\%, telah jatuh tempo 1-14 hari dicadangkan sebesar 10\%, telah jatuh tempo 14-20 hari dicadangkan sebesar $15 \%$, telah jatuh tempo 20-30 hari dicadangkan sebesar $20 \%$, dan telah jatuh tempo diatas 30 hari dicadangkan sebesar $25 \%$.

Dengan menggunakan aplikasi ini dapat memudahkan bagian akuntansi dan pemilik untuk mengetahui analisa umur piutang pelanggan dan penyajian laporan piutang lebih cepat.

\section{REFERENSI}

[1] Adhariani, M. 2017. “Analisis Sistem Pengendalian Intern Piutang Pada CV. Varia Rasa Banjarmasin" dalam Jurnal Socio Secretum Volume I(1)

[2] Afifah Nur Natalia, Soebandhi Santirianingrum, Wardhana Rony 2015. "Analisis Sistem Pengendalian Atas Piutang Pada PT GIS” dalam Jurnal Spirit Pro PatriaISSN : 2443-1532

[3] Baridwan,Zaki. 2014. Intermediate Accounting, Edisi 8. Yogyakarta: BPFE-UGM

[4] Dera Pratama Arya, Sondakh J Jullie, Warongan L D Jessy. 2016. “Analisis Efektivitas Sistem Pengendalian Internal Piutang Dan Kerugian Piutang Tak Tertagih Pada PT Surya Wenang Indah Manado" dalam Jurnal EMBA Vol 4(1)

[5] Dewi Trisna Antina. 2017. "Analisa Pengendalian Internal Piutang Dalam Meningkatkan Efektivitas Penagihan Piutang Pada PT Garam (Persero) Surabaya"

[6] Hery. 2015. Pengantar Akuntansi, Comprehensive Edition. Jakarta : PT.Grasindo.

[7] Indrajani. 2017. Perancangan Basis Data dalam All in 1. Jakarta: PT. Elex Media Komputindo.

[8] Jauhari Khairul Kawistara, Priyanto Hidayatullah. 2015. Pemrograman Web. Bandung: Penerbit Informatika.

[9] Mulyadi. 2016. Sistem Akuntansi, Edisi 4. Jakarta: Salemba Empat

[10] Maturidi, Ade Djohar. 2014. Metode Penelitian Teknik Informatika. Yoggyakarta:Deepulbish.

[11] Puspasari Aprilia, Suhendra Dony Asep, Endang Kusnaeni. 2019. "Pengendalian Internal Piutang Pada PT Saurindotex Mandiri Bekasi” dalam Jurnal MEA 3(1)

[12] Trisyanto. 2017.Analisis Dan Perancangan Basis Data. Surabaya: CV Garuda mas Sejahtera. 